\title{
Temporal and Spatial Dynamics of Carbon Fixation by Moso Bamboo (Phyllostachys pubescens) in Subtropical China
}

\author{
Guosheng Wen ${ }^{1,2,4,5}$ • Liyang Zhang ${ }^{2}$. \\ Ruming Zhang ${ }^{2}$ - Zhihong Cao ${ }^{1,3}$ - Guomo Zhou ${ }^{1,4}$ • \\ Hao Huang ${ }^{2}$ Minghung Wong ${ }^{3}$ \\ ${ }^{1}$ Zhejiang Provincial Key Laboratory of Carbon Cycling in Forest Ecosystems and Carbon Sequestration, \\ Zhejiang A \& F University, Lin' an 311300, People's Republic of China \\ ${ }^{2}$ School of Forestry and Biotechnology, Zhejiang A \& F University, Lin' an 311300, People's Republic of \\ China \\ ${ }^{3}$ Joint Laboratory of Soil and Environment Sciences, Hong Kong Baptist University, Kowloon Tong \\ Hong Kong SAR and Institute of Soil Science, CAS Nanjing, Nanjing 210008, People's Republic of \\ China \\ ${ }^{4}$ The Nurturing Station for the State Key Laboratory of Subtropical Silviculture, Zhejiang A \& F \\ University, Lin' an 311300, People's Republic of China \\ ${ }^{5}$ Author for Correspondence; e-mail: wgs@zafu.edu.cn \\ Published online: 9 June 2011 \\ (C) The Author(s) 2011. This article is published with open access at Springerlink.com
}

\begin{abstract}
To study the temporal and spatial dynamics of carbon fixation by Moso bamboo (Phyllostachys pubescens) in subtropical China, carbon fixation of leaves within the canopy of $P$. pubescens was measured with a LI-6400 portable photosynthesis system. The results showed that the capability of carbon fixation of $P$. pubescens leaves had obvious temporal and spatial dynamic variations. It was revealed that there were two peak periods and two low periods in the season variation of carbon fixation capability. Data also revealed that the capability of carbon fixation by five-year-old P. pubescens was more than that of one-year-old and three-year-old. Daily and seasonal carbon fixation showed a negative correlation with the $\mathrm{CO}_{2}$ concentration. The temporal and spatial dynamics of carbon fixation by $P$. pubescens described above provided a scientific basis for development of technologies in bamboo timber production.
\end{abstract}

Keywords Moso bamboo $\cdot$ Net photosynthetic rate Carbon fixation · Forest ecosystem $\cdot$ Phyllostachys pubescens

\section{Introduction}

Moso bamboo (Phyllostachys pubescens) is an important forest resource in subtropical China. Its special growth and cloning characteristics and artificial operation modes differentiates it from other types of forest ecosystem (Shi et al., 2005). In recent years, increasing research on global climate change and the carbon 
cycle of forest ecosystems have resulted in rapid expansion in area and industrial production of $P$. pubescens. This growth was enabled by many research achievements, such as carbon storage and its distribution characteristics, carbon density and its spatial distribution characteristics, gas exchange characteristics and the influence of different management mode on carbon storage of forests ecosystem (Lin et al., 2008a, b; Xiao et al., 2007; Zhou \& Jiang, 2004; Zhou et al., 2006). However, temporal and spatial dynamics of carbon fixation by $P$. pubescens entailed a substantial degree of uncertainty. There were several disputes about the dynamics of photosynthesis of $P$. pubescens. Research on photosynthetic capacity in distinct ages or different leaves was rare (Huang et al., 1989a, b; Qiu et al., 2002). In order to provide a scientific basis for development of technologies of carbon sinks in bamboo forest management and potential tapping of carbon fixation, a $15 \mathrm{~m}$ tall observation tower was built in a natural experimental field of $P$. pubescens in Lin'an, Zhejiang Province, China. Temporal and spatial dynamics of carbon fixation of $P$. pubescens and associated influencing were measured by LI-6400 portable photosynthesis system.

\section{Materials and Methods}

\section{Geography of Experimental Field}

A $15 \mathrm{~m}$ tall observation tower was built in an experimental field of $P$. pubescens forests in Linan, Zhejiang Province, China $\left(30^{\circ} 18^{\prime}-30^{\circ} 25^{\prime} \mathrm{N}\right.$ and $119^{\circ} 23^{\prime}-119^{\circ} 29^{\prime}$ E). The experimental field was in typical subtropical monsoon climate zone; warm, wet, with adequate sunshine and high rainfall, with one year divided into four distinct seasons with a short autumn and spring and long summer and winter. The annual mean air temperature was about $15.9^{\circ} \mathrm{C}$ the extreme highest temperature $41.2^{\circ} \mathrm{C}$, the lowest temperature $-13.1^{\circ} \mathrm{C}$ and average annual precipitation was $1,427 \mathrm{~mm}$.

\section{Sampling and Measurement}

Standard plots and sample plants of 1, 3 and 5 year-old $P$. pubescens were selected as test objects in the observation tower. The tower had three layers: upper layer, $12 \mathrm{~m}$; middle layer, $10 \mathrm{~m}$; lower layer, $8 \mathrm{~m}$. A LI-6400 portable photosynthesis system (LI-COR, USA) was used to determine photosynthetic characteristics of P. pubescens on clear days, and a SPAD-502 chlorophyll meter (Minolta, Japan) was used to determine relative chlorophyll content.

Seasonal changes of carbon sequestration of bamboo were determined from January 2009 to January 2010. Three bamboo plants in each age group of one, three, and five years-old were selected. Leaves were then randomly selected from the canopy and the light response curve was determined. SPSS 13.0 was used to fit the light response curve which was processed with MS Excel using the exponent function $P n=P_{\max }\left(1-C_{o} e^{-a P A R / P_{\max }}\right) . P n$ is net photosynthetic rate $\left(\mu \mathrm{mol} / \mathrm{m}^{2} / \mathrm{s}\right) . P_{\max }$ is maximum net photosynthetic rate $\left(\mu \mathrm{mol} / \mathrm{m}^{2} / \mathrm{s}\right)$ at light saturation point. $P A R$ is photosynthetic active radiation $\left(\mu m o l m^{-2} \mathrm{~s}^{-1}\right) . a$ is early 
quanta efficiency. $C_{o}$ is an index whereby the net photosynthetic rate tends to approach 0 under low light $\left(\mu \mathrm{mol} / \mathrm{m}^{2} / \mathrm{s}\right) . e$ is exponent function. The capability of carbon fixation is expressed Pmax (Bassman \& Zwier, 1991).

Three to five leaves were chosen randomly to determine daily changes and gas exchange parameters, from 8:00 am to 5:00 pm on clear days.

The Excel software was used to process data, the Sigma plot 10.0 was used to draw, and SPSS 13.0 was used for statistical analysis.

\section{Results}

Seasonal Variations of Carbon Sequestration Ability of Unevenly-Aged Bamboo

Bamboo forests are often unevenly-aged and forests with intensive management consist of 1 year, 3 year and 5 year-old bamboo plants, with bamboo older than 5 years cut for lumber. Pmax represented the seasonal variation of carbon sequestration ability of unevenly-aged bamboo (Fig. 1), which had two peaks and two depressions in a year. It rose gradually from January, reached the first peak in May to June, declined in July and August with photosynthetic capacity decreased, reached a second peak in October, and then decreased again in November to the second depression in December to February. In the peak period, Pmax of five-year old bamboo was significantly higher than one-year old and three-year old bamboo, and values were $20 \%$ and $38 \%$, respectively. However, the difference was not significant in the declining period. Pmax in the peak period was 4.5 times higher than in the decline period. Therefore, the carbon sequestration ability of bamboo can be further increased with improvement of traditional management mode.

Fig. 1 Seasonal variation of maximum net photosynthetic rate $(P \max )$ in different age of $P$. pubescens

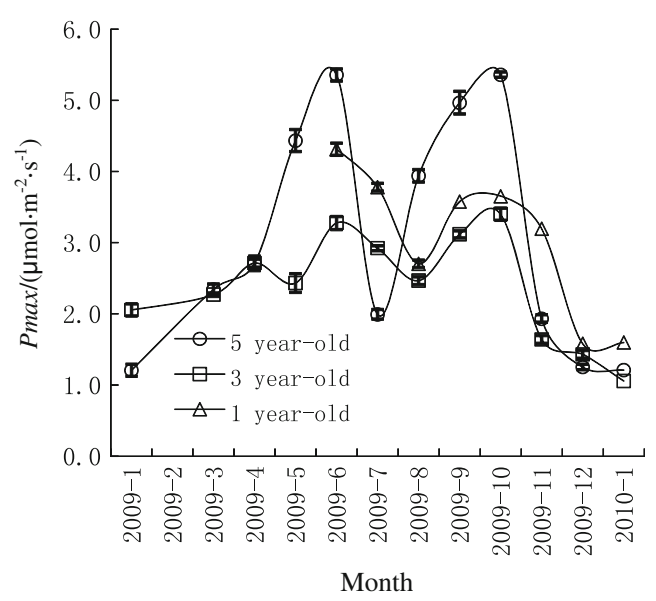

Springer 
Fig. 2 Diurnal changes in the net photosynthetic rate $(P n)$, air $\mathrm{CO}_{2}$ concentration $\left(\mathrm{CO}_{2} \mathrm{~S}\right)$, intercellular $\mathrm{CO}_{2}$ concentration (Ci) of $P$. pubescens

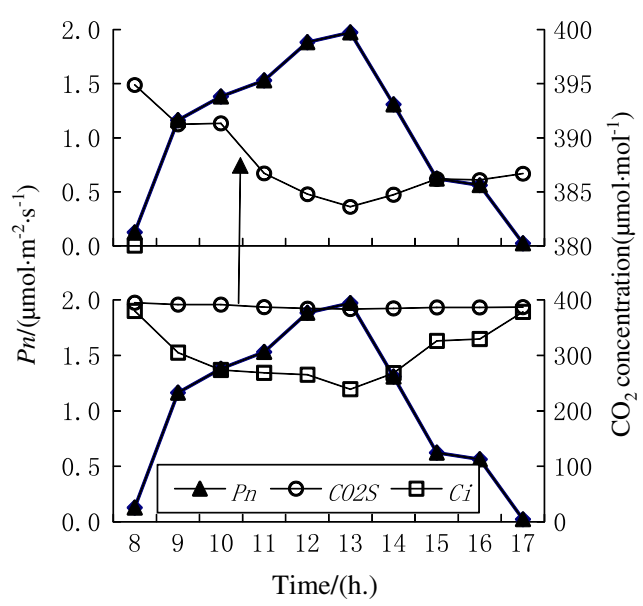

Daily Variation of Carbon Sequestration Ability of Bamboo and the Relationship with $\mathrm{Co}_{2}$ Concentration

The daily changes of net photosynthetic rate $(\mathrm{Pn}), \mathrm{CO}_{2}$ concentration of atmosphere $\left(\mathrm{CO}_{2} \mathrm{~S}\right)$ and intercellular carbon dioxide concentration $(\mathrm{Ci})$ are shown in Fig. 2. In the morning, $\mathrm{CO}_{2} \mathrm{~S}$ and $\mathrm{Ci}$ dropped gradually with rising $\mathrm{Pn}$, and $\mathrm{CO}_{2} \mathrm{~S}$ and $\mathrm{Ci}$ decreased to the minimum when $P n$ reached the maximum at 1:00 pm. Furthermore, $\mathrm{CO}_{2} \mathrm{~S}$ and $\mathrm{Ci}$ increased gradually with $\mathrm{Pn}$ decreased in the afternoon. $\mathrm{Pn}$ and $\mathrm{CO}_{2}$ concentration had a significant negative correlation because of the high photosynthetic rate that lowered the $\mathrm{CO}_{2}$ concentration, and the variation of $\mathrm{CO}_{2}$ concentration was significant in the cell scale than in the atmosphere scale (Fig. 3). In the day, when $P n$ changed from 0 to $2 \mu \mathrm{mol} / \mathrm{m}^{2} / \mathrm{s}, C i$ varied from 200 to $400 \mu \mathrm{mol} / \mathrm{mol}$, and the amplitude was $200 \mu \mathrm{mol} / \mathrm{mol}$, however, $C_{2} S$ changed from 385 to $395 \mu \mathrm{mol} / \mathrm{mol}$, and the amplitude was only $10 \mu \mathrm{mol} / \mathrm{mol}$.

Fig. 3 Relations of the net photosynthetic rate $(\mathrm{Pn})$ and air $\mathrm{CO}_{2}$ concentration $\left(\mathrm{CO}_{2} \mathrm{~S}\right)$, intercellular $\mathrm{CO}_{2}$ concentration $(\mathrm{Ci})$ of P. pubescens

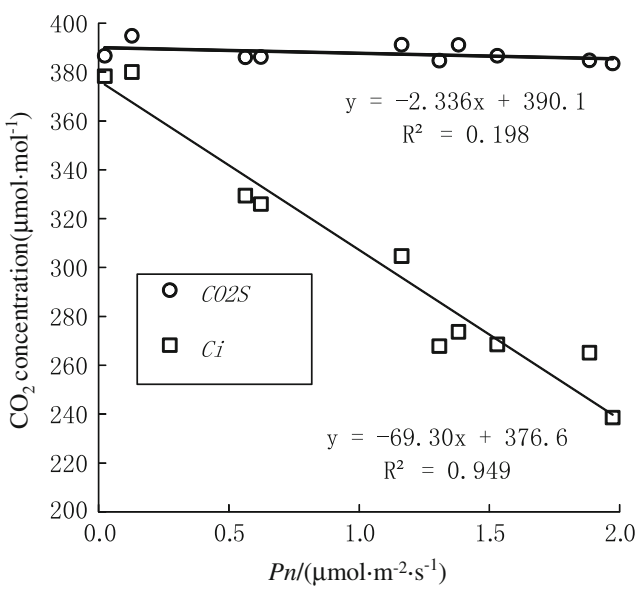


Table 1 Comparison of the maximum photosynthetic rate $(P \max )$ and relative chlorophyll content $(R C C)$, light saturation point $(L S P)$ in different forest crown of $P$. pubescens

\begin{tabular}{lccr}
\hline & upper layer & middle layer & \multicolumn{1}{c}{ low layer } \\
\hline $\operatorname{Pmax}\left(\mu \mathrm{mol} / \mathrm{m}^{2} / \mathrm{s}\right)$ & $5.77 \pm 1.86$ & $5.39 \pm 1.72$ & $5.21 \pm 1.67$ \\
$R C C($ relative value $)$ & $30.52 \pm 1.90$ & $31.93 \pm 2.08$ & $33.66 \pm 1.87$ \\
$L S P\left(\mu \mathrm{mol} / \mathrm{m}^{2} / \mathrm{s}\right)$ & $244 \pm 32$ & $211 \pm 36$ & $191 \pm 14$
\end{tabular}

\section{Spatial Variation of Carbon Sequestration Ability of Bamboo}

To compare the carbon sequestration ability of different layers of bamboo canopy, the upper layer, the middle layer and the lower layer leaves of the canopy were randomly chosen to determine the light response curve and the relative chlorophyll content, in order to calculate Pmax and LSP (Table 1). Pmax and LSP decreased gradually, and the relative chlorophyll content increased gradually from top to bottom of the canopy, which showed that $L S P$ significantly influenced the carbon sequestration ability of leaves from the different layers as compared to the relative chlorophyll content.

\section{Factors Affecting Carbon Sequestration Ability of Bamboo}

In order to analyze the influential factors of carbon sequestration ability of leaves of bamboo plants of different ages, monthly meteorological data of the mean temperature, precipitation, number of rainy days, and sunshine hours were recorded at the Lin'an weather station during the experimental period, in addition to leaf temperature, relative humidity of chamber, and $\mathrm{CO}_{2}$ concentration of the atmosphere. LSP was also recorded based on the light response curve, and the correlation coefficients between above factors and Pmax of different age bamboos were calculated (Table 2). P $\max$ was positively correlated with the mean temperature, precipitation, rainy days, sunshine hours, leaf temperature, relative humidity of chamber, and negatively correlated with $\mathrm{CO}_{2}$ concentration of atmosphere. The temperature had greater impact on the climate factors.

Table 2 CORREL of the maximum photosynthetic rate $(P \max )$ and environment factors of $P$. pubescens

\begin{tabular}{lccc}
\hline Pmax & 5 year old & 3 year old & 1 year old \\
\hline Air temperature $\left({ }^{\circ} \mathrm{C}\right)$ & 0.83 & 0.73 & 0.79 \\
Precipitation $(\mathrm{mm})$ & 0.14 & 0.01 & 0.15 \\
Day of Precipitation $(\mathrm{d})$ & 0.06 & 0.15 & -0.06 \\
Leaf temperature $\left({ }^{\circ} \mathrm{C}\right)$ & 0.79 & 0.69 & 0.77 \\
Relative humidity $(\%)$ & 0.59 & 0.54 & 0.62 \\
Time of sunlight $(\mathrm{h})$ & 0.57 & 0.44 & 0.61 \\
$\mathrm{CO}_{2}$ concentration $(\mu \mathrm{mol} / \mathrm{mol})$ & -0.65 & -0.52 & -0.67 \\
\hline
\end{tabular}




\section{Discussion}

Bamboo is one of the best agents for carbon sequestration in the subtropical areas of China. and is 2 to 4 times more effective than Chinese fir and pines of this area (Zhou et al., 2006). Our results showed two peaks of carbon sequestration within a year, from May to June, October, and two depressions, in the high temperature period of July to August and in the low temperature period and leaf displacement period. In the peak period, carbon sequestration ability of five-year-old bamboo was significantly higher than three-year-old bamboo and one-year-old bamboo. However, in the declining period, there was no significant difference in carbon sequestration ability among bamboos of different ages. It has been found that peak carbon sequestration appeared in June and November, which was identical with the study by Huang et al. (1989a, b). However, Huang et al. (1989a, b) found that the peak of carbon sequestration appeared in the summer, which was inconsistent with the paper by Huang et al. (2000). In this paper, monthly carbon sequestration ability was indicated by Pmax, which was calculated by fitting the light response curve. This method reduced an error which is caused by instantaneous changes of light intensity and this can better reflect the carbon sequestration ability. Carbon sequestration ability of different layers of bamboo canopy was upper layer $>$ middle layer $>$ lower layer, which was consistent with light saturation point of leaves. However the relative chlorophyll content was upper layer $<$ middle layer $<$ lower layer, which showed that light saturation point has greater impact on carbon sequestration than the relative chlorophyll content. Daily changes and seasonal changes of carbon sequestration of bamboo canopy were negatively correlated with the change of $\mathrm{CO}_{2}$ concentration, and were positively correlated with the mean temperature, precipitation, rainy days, monthly sunshine hours, leaf temperature, relative humidity of chamber and LSP. Therefore, we can use these results of temporal and spatial variation of carbon sequestration by bamboo canopy to improve the traditional production mode to increase carbon sequestration. Cutting and hooking tips were usually carried out from September to November. The purpose of hooking was to remove leaves and shoots in the upper layer, which can prevent bamboo from snow pressure and above five-year old bamboo usually was cut for lumber. However, the peak of carbon sequestration occur in September to November, therefore delaying hooking and cutting can increase carbon sequestration of bamboo. Therefore, it is suggested that the hooking should be carried out in December before snowfall, and cutting should be carried out in December to March.

Acknowledgments We thank the Program of National Natural Sciences Foundation of China (30771715, 30972397) for funding.

Open Access This article is distributed under the terms of the Creative Commons Attribution Noncommercial License which permits any noncommercial use, distribution, and reproduction in any medium, provided the original author(s) and source are credited. 


\section{Literature Cited}

Bassman, J. \& J. C. Zwier. 1991. Gas exchange characteristics of Populous trichocarpa, Populous deltoids and Populous trichocarpa X P. Deltoids clone. Tree Physiology 8(2): 145-159.

Huang, C. C., Y. Ge \& J. Chang. 2000. Studies on photosynthesis and respiration of blades of Phylloystachys pubescens in Eastern mid-subtropical Zone, China. Journal of Zhejiang Forestry Science and Technology 20(5): 14-46.

Huang, Q. M., D. J. Yang \& A. X. Gao. 1989a. Study on the Photosynthetic of Phylloystachys pubescens under different conditions. Bamboo Research 8(2): 8-16.

\& 1 . 1989b. Study on the Photosynthetic of Phylloystachys pubescens. Scientia Silvae Sinicae 25(4): 366-369.

Lin, Q. Y., J. Hu \& G. S. Wen. 2008a. Diurnal variations of photosynthesis in leaves of Phylloystachys pubescens in winter. Journal of Fujian College of Forestry 28(1): 61-64.

- J. X. Chen, S. Z. Yang, G. S. Wen. 2008b. Study on gas exchange of Phylloystachys pubescens in Tianmu Mountain. Journal of Zhejiang Forestry College 25(4): 522-526.

Qiu, E. F., C. J. Cheng, Y. C. Liang \& D. H. Cheng. 2002. Dynamic on chlorophyll concentration of leaves surface of different provenances of Phylloystachys pubescens. Journal of Fujian College of Forestry 22(4): 312-315.

Shi, J. M., Q. R. Guo \& G. Y. Yang. 2005. Study on the photosynthetic dynamic variation of Phylloystachys pubescens. Forest Research 18(5): 551-555.

Xiao, F. M., S. H. Fan \& S. L. Wang. 2007. Carbon storage and spatial distribution in Phyllostachys pubescens and Cunninghamia lanceolata plantation ecosystem. Acta Phytoecologica Sinica 27(4): 2791-2801.

Zhou, G. M. \& P. K. Jiang. 2004. Density, storage and spatial distribution of carbon in Phyllostachys pubescens Forest. Scientia Silvae sanicae 40(6): 20-24.

J. S. Wu \& P. K. Jiang. 2006. Effects of different management models on carbon storage in Phyllostachys pubescens Forests. Journal of Beijin Forestry University 28(6): 51-55. 